\title{
Successfully moving the library-temporarily
}

\author{
By Ellen Meltzer
}

\section{Planning, cooperation, flexibility, and a sense of bumor are key}

$\mathbf{W}$ hat could compel an incredibly busy California undergraduate library to move lock, stock, and barrel out of its fivestory building and back in again within a sevenmonth period? Seismic strengthening, that's what. A 1979 report by the engineering firm $\mathrm{H}$. J. Degenkolb \& Associates evaluating the seismic hazard of certain University of California buildings on the Berkeley campus states, "Moffitt Library has little dynamic resistance and will not even remotely meet present day earthquake requirements. Earthquake experience with this type of structure confirms that there is a major hazard of collapse."

At the close of the spring semester 1992, Moffitt was finally ready for its seismic work to begin, after years of discussion and planning. Planning, cooperation, flexibility, and a sense of humor were the keys to the successful moves.

\section{Who and what we moved}

Twenty-three staff members including a technical services section, circulation department, reference and collection development librarians, a media resources library, and administrative services section, student staff, files and equipment, a complicated phone system, and computer hook-ups had to be relocated into the Main Library (with one staff member going over to the Physics Library). In addition, records for the 10,000 or so items we moved over to Main originally (with room to grow up to $40,000)$ had to be tagged. The Systems Office wrote a program to page books from Moffitt, so that when an item in Moffitt appeared on the screen, the user was told how to "PAGE MOFF."

\section{Critical steps}

1. Planning a list of operations for each section of the library that would have to be on-going during the closure period was critical. In addition, we created lists of space and equipment needs for relocation.

2. Discussions with space planning and department heads in the Main Library to find suitable space in other locations for staff had to occur. The unions had to be notified regarding the relocation or reassignment of staff. I spoke personally to all Moffitt employees about where they would go during the surge period and about what they would be doing. Training plans had to be written for staff doing new assignments during the move. Keys had to be distributed to staff members for their new locations.

3. Coordination with other units (in this case, mainly from the Main Library) had to be done to find space in the Main stacks - already overcrowded with over 1,000,000 books-for an additional 40,000 volumes, including closed stack space for undergraduate reserves.

4. We had to have a system in place to separate out Moffitt books so they wouldn't get mixed in with Main Library materials. Circulation staff affixed lime green dots to the backs of the spines of all Moffitt books for the period we surged to Main. Lime green will always have a special meaning to the Circulation Staff in Moffitt!

5. We needed support from the Systems Office to develop a PAGE MOFF system on the Berkeley online catalog, GLADIS. Circ students and career staff also needed to be able to charge, discharge, and renew items with the location Moffitt as well as Main without having to logon 


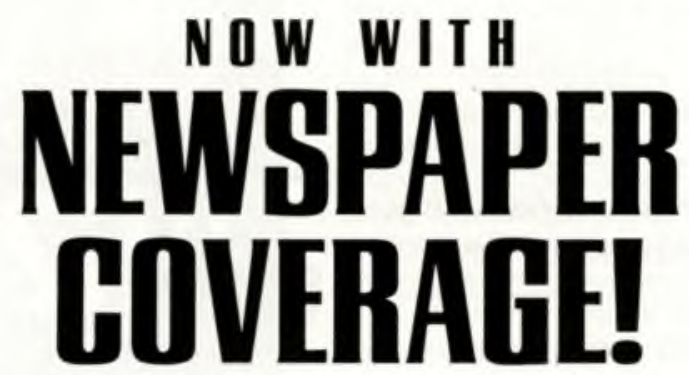

7 he H.W. Wilson Company now provides high-quality 1 indexing and abstracting of The New York Times and the Wall Street Journal in select Wilson databases!

Business Periodicals Index and Wilson Business Abstracts now include indexing and abstracting of articles from the Wall Street Journal as well as the Business Section of The New York Times. BPI contains indexing; $\boldsymbol{W B A}$ contains indexing and brief abstracts for every citation.

The Readers' Guide to Periodical Literature and Readers' Guide Abstracts provide complete coverage of The New York Times, except the Metropolitan section. The Readers' Guide provides indexing; $R G A$ includes both indexing and abstracting. Readers' Guide Abstracts Select Edition provides limited indexing with abstracts for The New York Times. The Science Section of The New York Times will be indexed in General Science Index as well.

THE H.W. WILSON COMPANY Sharing Knowledge Since 1898 950 University Avenue • Bronx, NY 10452 • 800-367-6770 
and logoff terminals. Notices regarding holds and overdues had to have the unit record adjusted to reference Main as the location, rather than Moffitt

All records for Moffitt books located in Main had to have the note added, "Shelved in Main." This was also the case for the 100 or so unique periodicals titles we brought with us. Main Library periodicals circulate while ours do not. Help screens on various subjects had to be written and added to GLADIS for the duration of the move (and then undone when we returned!).

We soon discovered how much our users appreciated and used the PAGE MOFF function. In fact, they paged many more books than they picked up, so we tried to discourage them from paging if the same book was on the shelf in Main (where we were already) or in a branch.

6. Public online catalogs had to be added to the Main Library to offset the loss of 29 Moffitt GLADIS/MELVYL terminals. Photocopiers also had to be moved to Main near the Reserves section, near the Moffitt periodicals, and in additional locations.

7. We had a two-hour window between 4:00 and 6:00 p.m. when construction was over for the day, and Circulation and Media Resources staff could retrieve books and videos from Moffitt. Students vied to retrieve books from the less dirty and noisy floors ( 4 and 5) rather than from the first and second floors where interior load-bearing walls were going up. The paging system had to be planned and coordinated with Space Planning and the contractors.

8. The entire Media Resources Center and a portion of its collections, about 1,200 videos, had to be relocated to another building across campus, Dwinelle Hall (there was no appropriate space in the Main Library) which housed the Office of Media Services. Office space had to be provided for the career staff member who would oversee MRC during the move, the online catalogs had to be made available, and access to the library's automated circulation subsystem, phone lines, and equipment including 20 video workstations had to be moved as well, all in a location outside the library.

9. Support was required from our Supply and Maintenance Division to move equipment and materials. Extra large book trucks were rented for the move of the initial 10,000 volumes. Support from the Systems Office to hook up all the equipment for staff and support from
Campus Telecommunications to have the phones rerouted to many different locations were essential to the move.

10. Signage had to be added to the Main Library to tell our users how to find staff and services such as Reserves Processing, two-hour reserves, Moffitt circulation and stacks, reference services, and alternate study spaces. Signs were needed in the entrance lobbies on the first and second floors, in the loan hall, in the stacks, and in the circulation staff area. The Library Graphics Office handled these, as well as a huge blue and gold (Cal's colors) sign as users approached the building telling them the building was closed and that services were relocated to Main.

\section{What could compel a busy Calffornia undergraduate library to move lock, stock, and barrel out of its five-story build- ing and back in again witbin a seven-month period?}

11. Coordination with campus to find alternate study space that students could use to offset the loss of 1,700 or so seats in Moffitt $\mathrm{Li}^{-}$ brary had to be arranged. Some space had to be made available for evening (until 2:00 a.m.) and weekend hours. This planning involved coordinating with the chancellor's office and campus housing services, as some of the dormitory dining commons were used after dinner for study space. The campus police and custodial services were also involved when we explored the possibility of using various spaces on campus and whether or not there were safe walk or shuttle routes, and if the buildings could be adequately cleaned. The classroom manager was brought in when we explored the use of clustered classrooms at nights for study. Many places were rejected for their lack of security and cost of maintaining them.

12. Publicity on campus in the form of flyers posted on the doors, distributed to students in the dormitories, articles in the faculty newsletter Library Briefings, the campus faculty/staff newspaper the Berkeleyan, and the student newspaper the Daily Californian informing users about the disruption had to be in place. Individual letters were also sent to faculty with information about placing materials on reserve. 
This was done well in advance of the actual move, discouraging faculty from placing too much on reserve, for example, the summer of our move. A series of "Moffitt Survival Guides" was made available to our users as the project progressed, keeping them informed of locations of services. A map and listing of alternate study hall locations was also widely distributed.

13. As acting head of Moffitt at the time of the move, I met several times with officers in the Associated Students of the University of California (ASUC) to discuss the move and how various aspects of it would be handled.

14. When we moved back to Moffitt, we had t-shirts commissioned by resident artist Gary Handman that declared, "I survived the Moffitt move!" These were given to all Moffitt staff and those in other locations who had helped us during the move period. The fact that all of the following departments played a critical part in our successful move either by providing support or by housing us gives you an idea of what a collaborative effort the move was: Main Circulation, Bibliographic Services Division, Catalog Department, Physics Library, South/Southeast Asia Library, Government Documents Department, Reference and Collection Development, Space Planning, Graphics, Systems, Periodicals, Conservation, Supply and Maintenance, Photocopy Service, Human Resources, Mail Room, the Associate University librarians and a number of campus units beyond the library. Our administrative assistant did a tremendous job of organizing all the details of the move. Most of all, the Moffitt staff was so psychologically prepared, that despite inconveniences and hardships such as crowding, lack of personal space, windowless rooms, or fourth floor rooms with no elevators, they displayed good spirit and flexibility throughout.

\section{What did we forget?}

What had we overlooked? Another environmental aberration in California (besides earthquakes) was that at the time of the move we were entering the seventh year of a drought. No one in Moffitt had considered seriously how we would move materials in the pouring rain. Of course, 1992/93 was the year the drought ended, and we did have to skip entirely a few days of paging or use tarps and umbrellas when paging materials.

When we did move back, and some staff complained that Moffitt was dirty, I regretted that all the staff had not seen the building at its lowest, grimiest point. Flimsy plastic walls had been erected to keep the construction dirt and dust out of the rest of the building, but the moment these were erected, the workmen walked through them. The dust walked, too, into every nook and cranny of the library. The building looked like it would never be habitable again. The staff offices, which we had been assured would remain clean since they were separated by doors, looked like Pompeii after the volcano erupted. The Conservation Department vacuumed every book in the collection with special vacuums suited to the task. To me, the library looked remarkably spic and span when we retumed, but to those who had not visited it regularly, the layer of fine dust still remaining made the building seem dirty.

While the Moffitt staff was prepared for the move in all its details, as well as emotionally, the staffs into whose units we moved were not all so well prepared mentally. There was some resentment when we encroached on others' space. We were viewed by some, I'm afraid, as dreaded in-laws who extend a visit far too long. For the most part though, this was not a problem, and when people were reminded that it was only temporary, they gritted their teeth and bore it.

When I mentioned to the library architect that it was far more difficult to move back into the building than it had been moving out, he nodded in agreement, and said that was always the case. I could have used this information in advance as we crankily moved back into our old space, finding it harder to fit everything back in than it had been to just pick up the bare essentials and walk out.

The greatest advantage of the move was that we had the opportunity to get to know our colleagues better, both to leam from and teach them. New alliances were built and old enmities discarded.

Our overriding concern in closing down Moffitt had been whether or not we would be able to serve our users well. We discovered in the period from June of 1992 to January of 1993 that students and faculty were far more understanding than we imagined they would be, and that they took the inconveniences in stride. Our years of planning had paid off. As is the case so often, the planning and imagining what could go wrong were much worse than the actual events. And now the prospect of being "pancaked" in Moffitt (as one report put it) during the next "big one" is far less likely. 


\section{"THE HISTORY OF EVERY CENTURY BEGINS IN THE HEART OF A MAN OR A WOMAN." \\ - WilLa CATHER}

Czech and

Slovakian

Biographical

Archive

\section{Index}

Biographique

Français

Edited by Helen Dwyer
Drawing on 280 sources authored between 1559 and the middle of the 20th century, this cumulation covers some 110,000 individuals who have played a significant role in the development of Czech history and culture.

$1993-1996 \bullet 12$ installments $\bullet$ c. 550 fiche (24X)

Silver $\$ 14,000 \bullet$ Diazo $\$ 12,870$

A comprehensive biographical dictionary in its own right, this index to the Archives Biographiques Françaises provides basic biographical information, a listing of citations to original biographical works, and fiche reference numbers for the full-text of biographies on each individual.

1993 • (0-86291-801-4 • 4 volumes $\bullet$ c. 2,400 pages • $\$ 925.00$

\section{American Biographical Index}

Provides basic biographical information: name, birth and death dates or floruit, occupation, listings of source works in which entries appear, as well as the fiche reference number for each individual.

$1993 \cdot 0-86291-382-9 \cdot 6$ volumes $\bullet 3,274 \mathrm{pp}$. $\bullet \$ 1,075,00$

(Customers who purchase the American Biographical Archive receive one copy of the Index free of charge.)

Polish Biographical Archive

The Jewish Biographical Archive

Compiled by Hilmar Schmuck Advising Editor Pinchas Lapide
Offering valuable insight into three centuries of Polish history and culture, this archive encompasses 150 works published from the 17th through the 20th century. Contains biographies of native Poles and immigrants, as well as the many prominent individuals forced to emigrate from their homeland.

$1992-1995 \cdot 12$ installments $\bullet$ c. 550 fiche $(24 X)$

Silver $\$ 12,870$ - Diazo $\$ 11,700$

Compiling information from over 200 biographical reference works and Jewish encyclopedias dating from the 17th century to 1948, The Jewish Biographical Archive features biographical articles on Jews from all over the world and throughout the ages, from all walks of life and all classes.

1994 - 1996 • c, 650 fiche $(24 X)$ - Silver: \$14,000† - Diazo: \$12,300† $\dagger$ Subscription price until 3/31/94.

For more information about

other Biographical Archives, please contact Walter Jaffe at 908/6658630.

\section{K.G. Saur}

A Reed Reference Publishing Company

Prices are subject to change without notice.

121 Chanlon Road, New Providence, NJ 07974 